\title{
Principios fundamentales del Proceso Civil Transnacional
}

\author{
Geoffrey C. Hazard Jr., Rolf Stürner, \\ Michele Taruffo y Antonio Gidi
}

\section{Jurisdicción}

La jurisdicción sobre las partes, los bienes y el objeto del litigio se ejercerá de acuerdo con los principios generalmente aceptados en el derecho internacional, incluidos los tratados internacionales suscritos por el estado del foro.

\section{Independencia, imparcialidad y competencia del tribunal}

2.1 En la resolución de los litigios transnacionales el tribunal actuará con imparcialidad y gozará de independencia judicial, incluida una inamovilidad razonable y libertad frente a injerencias externas.

2.2 Se establecerá un procedimiento para hacer valer las causas de abstención y recusación.

2.3 Los jueces competentes para decidir litigios transnacionales tendrán una acreditada experiencia, así como suficientes conocimientos jurídicos, tanto en derecho sustantivo como procesal.

\section{Igualdad y derecho de defensa}

3.1 El tribunal garantizará la igualdad de oportunidades de defensa a las partes. Ello implica el derecho a realizar alegaciones de hecho y de derecho y a presentar los medios de prueba de conformidad con la ley procesal aplicable, con independencia de cuál sea la naturaleza de la disputa, y la nacionalidad o residencia de las partes. 
3.2 No podrá exigirse a una parte la constitución de fianza para responder de las costas o de los daños y perjuicios, por el hecho de no tener su domicilio en el estado del foro.

3.3 Las normas de competencia territorial deberán asegurar que el tribunal que conoce del litigio sea razonablemente accesible a las partes $\mathrm{y}$ a sus abogados.

3.4 El tribunal garantizará a las partes la oportunidad de argumentar frente a la prueba practicada por la parte contraria.

3.5 El tribunal tomará en cuenta cada una de las alegaciones jurídicas y fácticas relevantes que hayan sido aducidas por las partes.

3.6 El litigio deberá resolverse con la debida celeridad.

\section{El derecho a la asistencia letrada}

4.1 Las partes gozarán del derecho a la asistencia letrada. Podrán designar un abogado que esté habilitado para ejercer ante el tribunal del foro, y otro que lleve a cabo funciones de asesoramiento, sin necesidad en este último caso de que esté habilitado en el foro.

4.2 Se respetará la independencia profesional de los abogados.

\section{Derecho de audiencia y actos de comunicación}

5.1 Las partes tienen derecho a ser informadas de manera razonable de aquellos procesos que afecten a sus intereses, tanto de la incoación del litigio como de las actuaciones importantes que se produzcan a lo largo del proceso.

5.2 En particular, la demanda será comunicada formalmente al demandado a través de los medios razonables que sean más efectivos. Igualmente se le advertirá de la posibilidad de ser condenado en rebeldía si no contesta dentro del plazo establecido.

5.3 Cada una de las partes deberá tener la oportunidad de conocer y responder a las alegaciones fácticas y jurídicas realizadas por la parte contraria.

5.4 En aquellos casos en que el tribunal, a instancia de parte, resuelva sin que se haya podido trasladar la comunicación a la parte contraria, ésta tendrá derecho a que se revise esa resolución «de novo". 
5.5 Cada parte, en el debido momento, hará saber a la contraria cuáles son los hechos en los que se funda la demanda o la contestación, así como los argumentos legales que serán invocados, de tal manera que cada una de las partes tenga la oportunidad de preparar adecuadamente su defensa.

\section{Ley aplicable}

La determinación de la ley aplicable, tanto a las cuestiones procesales como a las sustantivas, deberá realizarse de conformidad con los principios aceptados por las normas de derecho internacional privado.

\section{Estructura del proceso}

7.1 El proceso se dividirá en tres fases: fase de alegaciones, fase de instrucción ("pretrial" en la terminología del common law), y audiencia plenaria ("trial" en la terminología del common law).

7.2 En la fase de instrucción el tribunal resolverá cuestiones preliminares, controlará el acceso a los medios de prueba y la posible exhibición y práctica de prueba, y establecerá el calendario para las actuaciones subsiguientes.

7.3 Toda la prueba que no pudiera practicarse en la fase de instrucción se practicará en la audiencia plenaria siguiendo el principio de concentración.

8. Iniciación del proceso a instancia de parte y determinación del objeto del proceso

8.1 El litigio se iniciará a instancia de parte con la presentación de la demanda. En ningún caso se iniciará de oficio.

8.2 El objeto del proceso quedará determinado por las pretensiones y excepciones alegadas por las partes en la demanda y contestación respectivamente. Esas pretensiones y excepciones servirán de base para apreciar la litispendencia y la preclusión. 
8.3 Las partes podrán disponer de la finalización del proceso mediante desistimiento, mediante allanamiento parcial o total, o mediante transacción.

\section{Las funciones del tribunal en la dirección y desarrollo del proceso}

9.1 El tribunal velará por el adecuado avance del proceso, pudiendo ejercer la discrecionalidad judicial con el fin de lograr que el litigio se resuelva de manera justa y dentro de un plazo razonable.

9.2 El tribunal decidirá acerca de la relevancia de la prueba y la validez de los argumentos jurídicos.

9.3 El tribunal, tras consultar a las partes, fijará el orden en el cual se resolverá cada una de las cuestiones, así como los términos, los plazos preclusivos, y las fechas para la celebración de las audiencias.

10. Potestad judicial en el control del procedimiento; proporcionalidad

10.1 El tribunal tendrá autoridad para sancionar a las partes que incumplan o se nieguen a cumplir las órdenes judiciales o actúen en contra de las reglas de la buena fe procesal.

10.2 Las sanciones serán razonables y su alcance se fijará en función de la importancia y cuantía del objeto del litigio, así como de las intenciones de las personas cuya conducta se pretende sancionar.

\section{Principios rectores de la actuación de las partes}

11.1 Las partes respetarán las reglas de la buena fe procesal en sus actuaciones ante el tribunal como frente a las otras partes.

11.2 Las partes se abstendrán de plantear demandas o excepciones temerarias.

11.3 Las partes tienen la carga de alegar los hechos y practicar la prueba que funde sus pretensiones y excepciones. También habrán de informar al tribunal y a las otras partes acerca de la prueba que pretenden practicar y los argumentos legales sobre los cuales habrá de pronunciarse el tribunal. 
11.4 Los fundamentos de hecho y de derecho se presentarán de manera detallada en la demanda o en la contestación.

11.5 La falta de respuesta dentro del plazo establecido frente a la demanda, la contestación o cualquier otra alegación que requiera ser contestada, podrá servir de base para considerar admitidas las alegaciones no contestadas.

1 1.6 Las partes deberán cooperar en el adecuado desarrollo del proceso y en la práctica de la prueba.

\section{Modificación de la demanda y contestación}

12.1 En la fase de instrucción, las partes podrán modificar de manera razonable su demanda o su contestación, dando noticia de ello al tribunal y a las demás partes.

12.2 Con el fin de evitar una injusticia y siempre que ello no suponga un perjuicio para la otra parte, también será admisible introducir esas modificaciones en la audiencia plenaria.

\section{El derecho a la prueba y el deber de aportación de pruebas}

13.1 Las partes tienen, salvo supuestos excepcionales, derecho a acceder a toda la información y pruebas no objeto de exención que sean relevantes.

13.2 Las partes tienen derecho a realizar declaraciones con efectos probatorios. Tendrán también la oportunidad de proponer y practicar prueba relevante, incluida la prueba pericial, dentro de los términos razonables.

13.3 El interrogatorio de los testigos, las partes y los peritos se efectuará conforme a las leyes del foro. Así, el interrogatorio podrá estar dirigido inicialmente por las partes (como en los sistemas de common-law), o bien por el tribunal (como en los sistemas jurídicos continentales).

13.4 Las partes tendrán la oportunidad de realizar preguntas adicionales tanto en los interrogatorios dirigidos inicialmente por el juez como aquellos en que son dirigidos inicialmente por la parte contraria.

13.5 En la fase de instrucción cada parte podrá solicitar de las demás la exhibición de pruebas relevantes que se encuentren en su posesión o 
bajo su control. La parte requerida no podrá negarse a la exhibición requerida basándose en el argumento de que esa prueba le puede resultar adversa.

13.6 Las partes tienen derecho a obtener, dentro de unos límites razonables, el descubrimiento de pruebas respecto de terceros.

13.7 El tribunal podrá extraer conclusiones adversas para la parte que incumpla con el requerimiento de exhibición de prueba, cuando existan elementos suficientes que permitan deducir que esa prueba se encuentra en su poder o bajo su control. Iguales conclusiones podrá extraer el tribunal en el caso de que la parte requerida se niegue a colaborar de conformidad con lo dispuesto en las normas que regulan el proceso.

\section{Exenciones probatorias}

14.1 El tribunal respetará las exenciones probatorias generalmente aceptadas, tales como el derecho a no autoincriminarse y el derecho a no revelar las comunicaciones profesionales con el abogado y las conversaciones privadas con el cónyuge.

14.2 El tribunal respetará las exenciones que afecten a terceros de conformidad con la ley del foro, incluyendo la determinación de la ley aplicable.

\section{Terceros}

15.1 Los terceros que acrediten un interés legítimo en la causa tendrán la oportunidad de participar en el proceso con los mismos derechos y deberes que los litigantes iniciales.

15.2 Los terceros colaborarán en el adecuado desarrollo del proceso y en la práctica de la prueba. Ello incluye la obligación de cumplir los deberes relativos al descubrimiento y exhibición de pruebas.

\section{Oralidad y actuaciones escritas}

16.1 Siempre que sea posible, las declaraciones de los testigos, de las partes $y$ de los peritos se efectuarán oralmente, salvo que las partes, con la autorización del tribunal, acuerden otra cosa. 
16.2 También podrán limitarse los testimonios orales a las preguntas adicionales planteadas después del interrogatorio escrito dirigido a los testigos principales o a los peritos.

16.3 Las pretensiones, las objeciones procesales y las argumentaciones jurídicas deberán presentarse por escrito, pero las partes podrán completar oralmente la fundamentación de cuestiones sustantivas o procesales.

\section{Publicidad}

La audiencia plenaria (juicio) y los autos serán públicos, salvo aquellás materias que estén protegidas por el derecho a la confidencialidad.

\section{Carga de la prueba y reglas probatorias}

Conforme a las reglas del foro, el demandante tiene la carga de probar los hechos que fundan su pretensión. El demandado tiene la misma carga respecto de los hechos que fundan las excepciones que alega en su defensa

19. Deberes judiciales respecto de la aplicación del derecho y la apreciación de los hechos

19.1 El tribunal tiene la función de determinar, después de dar audiencia a las partes, cuál es el fundamento jurídico de su decisión.

19.2 El tribunal podrá fundar su decisión en principios jurídicos, hechos o elementos probatorios que no hayan sido aportados por las partes, sólo después de que las partes hayan tenido oportunidad de pronunciarse al respecto y hayan podido introducir modificaciones en sus alegaciones.

19.3 La práctica de la prueba y la fundamentación jurídica podrá presentarse ante uno de los magistrados en quien delegue el tribunal. Si se estima necesario el tribunal también podrá delegar la práctica de la prueba en otra persona adecuada.

19.4 El tribunal podrá ordenar la práctica de la prueba a instancia de parte o de oficio. 
19.5 Será admisible todo tipo de prueba relevante no objeto de exención, incluidas las declaraciones de las partes.

19.6 La fijación de los hechos se realizará sobre la base de la prueba practicada en el proceso, y de conformidad con el principio de la libre valoración de la prueba.

19.7 El tribunal controlará la admisión y utilidad de la prueba, indicando los hechos relevantes que requieren ser probados, así como el tipo de prueba requerida para decidir sobre esos hechos.

$19.8 \mathrm{El}$ tribunal podrá designar un perito para que declare sobre cualquier cuestión relevante, siempre que la prueba pericial sea apropiada. Las partes podrán solicitar la práctica de la prueba pericial por un perito de su elección, sobre cualquier cuestión relevante y para la cual la prueba pericial resulte apropiada.

19.9 La audiencia plenaria (el juicio) se celebrará en presencia del juez o jueces que dictarán la sentencia.

\section{Decisión y motivación de la sentencia}

20.1 Concluido el juicio, el tribunal dictará sentencia de inmediato. En la sentencia se indicarán los recursos que contra ella procedan.

20.2 La sentencia estará motivada jurídica y fácticamente.

\section{Transacción}

21.1 Entre las funciones que corresponden al juez está la de intentar que las partes lleguen a un acuerdo cuando ello resulte posible. El tribunal instará a las partes a acudir a procedimientos previos, a medidas de resolución alternativa de controversias, y a que lleguen a acuerdos en cualquier estado del proceso.

21.2 Las partes deberán cooperar en la búsqueda de una resolución negociada. 


\section{Costas}

22.1 La parte vencedora será reembolsada de las costas razonables del proceso, en las que se incluirán los honorarios de abogados, o la parte sustancial de los mismos que el tribunal considere justa y adecuada.

22.2 El tribunal podrá denegar la imposición de costas a favor de la parte vencedora, si existe una clara justificación para ello.

\section{Decisión definitiva}

Sin perjuicio del derecho a recurrir en apelación, la sentencia será definitiva y, como regla, ejecutable de inmediato.

\section{Apelación}

24.1 Se garantiza a las partes el derecho a la apelación en los mismos términos en que se garantice ese derecho en la ley del foro para procesos análogos.

24.2 El objeto de la apelación queda limitado a las acciones, excepciones, reconvenciones y prueba aducidas en la primera instancia. 